\title{
Simvastatin potentiates doxorubicin activity against MCF-7 breast cancer cells
}

\author{
BENJAPORN BURANRAT ${ }^{1}$, WANWISA SUWANNALOET ${ }^{2}$ and JARINYAPORN NAOWABOOT ${ }^{3}$ \\ ${ }^{1}$ Faculty of Medicine, Mahasarakham University, Talad, Maha Sarakham 44000; ${ }^{2}$ College of Medicine and Public Health, \\ Ubon Ratchathani University, Ubon Ratchathani, Warin chamrap, Ubon Ratchathani 34190; ${ }^{3}$ Division of Pharmacology, \\ Department of Preclinical Science, Faculty of Medicine, Thammasat University, Rangsit, Pathum Thani 12120, Thailand
}

Received August 7, 2015; Accepted February 7, 2017

DOI: $10.3892 / \mathrm{ol} .2017 .6783$

\begin{abstract}
Simvastatin is a low density lipoprotein-lowering drug that is widely used to prevent and treat cardiovascular disease by inhibiting the mevalonate pathway. Simvastatin also exhibits inhibitory effects on a number of types of cancer. In the present study, the effects of simvastatin on the activity of doxorubicin in the breast cancer MCF-7 cell line, and the mechanisms by which this interaction occurs were investigated. The effect of simvastatin and doxorubicin treatment, alone and in combination, on the growth of MCF-7 cells was evaluated by a sulforhodamine B and colony formation assay. To delineate the mechanisms of cell death, the following parameters were measured: Reactive oxygen species (ROS) production using the fluorescence probe dihydroethidium; caspase 3 activity by the fluorometry method; gene expression by quantitative polymerase chain reaction; and apoptotic- and proliferative-related protein levels by western blotting. MCF-7 cell proliferation was significantly suppressed by $24-48 \mathrm{~h}$ treatment with simvastatin alone. Doses of 10-50 $\mu \mathrm{M}$ simvastatin also enhanced the cytotoxicity of doxorubicin against MCF-7 cells in a dose-dependent manner, and decreased the colony-forming ability of MCF-7 cells. Simvastatin alone or in combination with doxorubicin significantly increased ROS levels. Combination treatment significantly decreased expression of the cell cycle regulatory protein Ras-related $\mathrm{C} 3$ botulinum toxin substrate 1 and numerous downstream proteins including cyclin-dependent kinase (Cdk) 2, Cdk4 and Cdk6. Additionally, simvastatin in combination with doxorubicin significantly induced expression of the cyclin-dependent kinase inhibitor $\mathrm{p} 21$, increased cytochrome $\mathrm{c}$ and caspase 3 expression and reduced cyclin D1 expression. In conclusion, simvastatin acts synergistically with the anticancer drug
\end{abstract}

Correspondence to: Dr Benjaporn Buranrat, Faculty of Medicine, Mahasarakham University, 296 Nakhornsawan Road, Talad, Maha Sarakham 44000, Thailand

E-mail: buranrat@gmail.com

Key words: simvastatin, doxorubicin, breast cancer, Ras-related C3 botulinum toxin substrate 1 , caspase 3 doxorubicin against MCF-7 cells, possibly through a downregulation of the cell cycle or induction of apoptosis. Although additional studies are required, simvastatin and doxorubicin combination may be a reasonable regimen for the treatment of breast cancer.

\section{Introduction}

Breast cancer is the most common type of malignancy, and the leading cause of cancer-associated female mortality, in a number of countries $(1,2)$ Chemotherapy with or without resection of the tumor is the only known treatment strategy for long-term survival, and survival is limited with standard chemotherapeutic options (3). Breast cancer cells exhibit intrinsic and acquired resistance to numerous anticancer drugs (4), this is a major problem for the effective treatment of breast cancer (5). Improved treatment protocols and alternative chemotherapeutic strategies are therefore required.

Statins competitively inhibit 3-hydroxy-3-methylglutaryl-coenzyme A (HMG-CoA) reductase, the rate-limiting enzyme in cholesterol biosynthesis (6), and are used to treat hyperlipidemia by reducing serum lipids such as cholesterol and triglycerides $(7,8)$. This activity, combined with their protective effects on the blood vessels and heart, allows statins to be used in the treatment and prevention of cardiovascular events $(9,10)$. In addition, statins perform roles in immune regulation (11), the inhibition of inflammation (12) and the modulation of angiogenesis (13). Statins also exhibit anticancer activities $(14,15)$, decrease cellular proliferation (15-17) and induce apoptosis $(15,18,19)$ in breast, colorectal, lung, prostate and pancreatic cancer (20). Notably, statins inhibit cancer cell growth in vivo and decrease metastasis at clinically therapeutic doses (21).

The suppression of HMG-CoA reductase results in the reduction of several important cholesterol intermediates, including mevalonate, geranylgeranyl pyrophosphate (GGPP) and farnesyl pyrophosphate (FPP) (22). These proteins are necessary for the post-translational modification of intracellular G-proteins, including Rho, ras-related C3 botulinum toxin substrate (Rac) and Ras, which regulate cellular mechanisms including cytoskeletal reorganization and cellular transformation, migration, invasion and proliferation (23). Statins activate cancer cell death, including apoptosis, via a reduction of GGPP 
and FPP levels. Additionally, Ras-related C3 botulinum toxin substrate 1 ( RAC1) regulates and modulates several signaling pathways that control cellular proliferation (24), and direct inhibition of RAC1 activity or gene expression induces cell cycle arrest and apoptosis in breast cancer cells (25).

In clinical studies, the role of statins in cancer treatment remains debatable, and appears to be dependent on the molecular identity of the type of cancer. In order to better understand the interaction between statins and breast cancer cells, the ability of simvastatin to potentiate the doxorubicin-induced inhibition of cellular proliferation and apoptosis using the MCF-7 cancer cell line was investigated. It was hypothesized that simvastatin sensitizes MCF-7 cells to doxorubicin, and may be a viable strategy for improving the efficacy of other anticancer drugs against breast cancer.

\section{Materials and methods}

Materials. Dulbecco's modified Eagle's medium(DMEM), fetal bovine serum and other cell culture reagents were purchased from Gibco; Thermo Fisher Scientific, Inc. (Waltham, MA, USA). Simvastatin (cat. no. s6196), doxorubicin (cat. no. D1515), protease inhibitor cocktail (cat. no. P8340), dihydroethidium (DHE; cat. no. D7008), radioimmunoprecipitation assay (RIPA) lysis buffer (cat. no. R0278), sulforhodamine B (SRB; cat. no. s1402) and a caspase 3 activity assay kit (cat. no. CASP3F-1KT) were obtained from Sigma-Aldrich; Merck KGaA (Darmstadt, Germany). The primary antibodies against cyclin-dependent kinase inhibitor 1 (p21; cat. no. 2947), caspase 3 (cat. no. 9662), cytochrome c (cat. no. 4272), cyclin D1 (cat. no. 2922), $\beta$-actin (cat. no. 4967) and the secondary anti-rabbit immunoglobulin $\mathrm{G}$ horseradish peroxidase (HRP)-linked antibody (cat. no. 7074) were purchased from Cell Signaling Technology, Inc. (Danvers, MA, USA). iScript reverse transcription Supermix for reverse transcription quantitative polymerase chain reaction (RT-qPCR; cat. no. 170-8841) and SsoFast EvaGreen Supermix (cat. no. 172-5200) were supplied by Bio-Rad Laboratories, Inc. (Hercules, CA, USA).

Cell line and cell culture. The human breast cancer MCF-7 cell line was obtained from the American Type Culture Collection (ATCC; Manassas, VA, USA) and maintained according to ATCC's recommendations at $37^{\circ} \mathrm{C}$ and $5 \% \mathrm{CO}_{2}$ in DMEM medium supplemented with $10 \%$ fetal bovine serum, $100 \mathrm{U} / \mathrm{ml}$ penicillin $\mathrm{G}$ and $100 \mu \mathrm{g} / \mathrm{ml}$ streptomycin. The DMEM media was renewed every 2-3 days, trypsinized with $0.25 \%$ trypsin-EDTA and subcultured in the same media.

Cell viability assay. The SRB assay was used to determine the effect of simvastatin and doxorubicin, alone and in combination, on the viability of MCF-7 cells. A 96-well plate was seeded with $1 \times 10^{4} \mathrm{MCF}-7$ cells/well and incubated for $24 \mathrm{~h}$ at $37^{\circ} \mathrm{C}$. Subsequent to exposure to $0-100 \mu \mathrm{M}$ simvastatin for 24-48 h, 0-10 $\mu \mathrm{M}$ doxorubicin for 24-48 $\mathrm{h}$ and in combination (cells were treated with $0-100 \mu \mathrm{M}$ simvastatin with or without $1 \mu \mathrm{M}$ doxorubicin for $24 \mathrm{~h}$ ) at $37^{\circ} \mathrm{C}$, the cultured cells were fixed with ice-cold $10 \%$ trichloroacetic acid and stained with $0.4 \% \mathrm{SRB}$ for $30 \mathrm{~min}$ at room temperature. Excess dye was removed by rinsing several times with $1 \%$ acetic acid, and protein-bound dye was dissolved with $200 \mu 110 \mathrm{mM}$ Tris base solution for the determination of absorbance with a microplate reader with a filter wavelength of $540 \mathrm{~nm}$.

Colony formation assay. Approximately $800 \mathrm{MCF}-7$ cells were seeded in 6-well plates and allowed to grow for $24 \mathrm{~h}$ at $37^{\circ} \mathrm{C}$. The cells were then treated with $0-50 \mu \mathrm{M}$ simvastatin and in combination of $0-50 \mu \mathrm{M}$ simvastatin with or without $0.5 \mu \mathrm{M}$ doxorubicin treatment for $24 \mathrm{~h}$ at $37^{\circ} \mathrm{C}$. Following this, the cells were washed with PBS and fresh medium was added. The cells were then grown for another 14 days. Subsequently, the DMEM medium was discarded, the cells were washed with PBS buffer three times, fixed with $100 \%$ methanol at $-20^{\circ} \mathrm{C}$ for $1 \mathrm{~h}$, stained with $0.5 \%$ crystal violet in $100 \%$ methanol for $1 \mathrm{~h}$ at room temperature, washed with tap water, and the colonies were then viewed and captured using a digital camera (Nikon D3100, Nikon Corporation, Tokyo, Japan). Colonies containing $>50$ individual cells were counted using Image-Pro Plus software version 2.0 (Media Cybernetics, Inc., Rockville, MD, USA).

Reactive oxygen species ( $R O S$ ) production assay. Intracellular ROS generation was measured using the cell-permeable fluorescent probe, DHE. Black 96-well plates were seeded with $\sim 1 \times 10^{4} \mathrm{MCF}-7$ cells/well and incubated for $24 \mathrm{~h}$ at $37^{\circ} \mathrm{C}$. The medium was discarded and the cells were washed with PBS. The cells were then treated with $0-50 \mu \mathrm{M}$ of simvastatin alone, or $50 \mu \mathrm{M}$ simvastatin in combination with $1 \mu \mathrm{M}$ doxorubicin, for $90 \mathrm{~min}$. The cells were then assessed for ROS production by incubation with $25 \mu \mathrm{M} \mathrm{DHE}$ in serum-free medium, in a $5 \% \mathrm{CO}_{2}$ atmosphere, at $37^{\circ} \mathrm{C}$, for $90 \mathrm{~min}$, in the dark. The fluorescence intensity was measured at a $518 \mathrm{~nm}$ excitation and $605 \mathrm{~nm}$ emission wavelength on a fluorescence microplate reader. The data were expressed as the percentage of ROS relative to the untreated controls.

Caspase 3 activity assay. Caspase 3 activity was measured using fluorimetric assay kits (Sigma-Aldrich; Merck KGaA) according to the manufacturer's protocol. Subsequent to treatment with the test compounds for $24 \mathrm{~h}$, the medium was removed, the cells were trypsinized and the cell pellet was lysed with cell lysis buffer on ice for $10 \mathrm{~min}$. The lysed pellet was then centrifuged $\left(10,000 \times \mathrm{g}, 4^{\circ} \mathrm{C}, 30 \mathrm{~min}\right)$, and protein concentrations were measured with Bradford's reagent (Bio-Rad Laboratories, Inc.), using albumin as a standard. Briefly, $50 \mu 1$ of cell protein or the albumin standard was mixed with $200 \mu \mathrm{l}$ Bradford reagent and incubated for $15 \mathrm{~min}$ at room temperature in the dark. The absorbance at $620 \mathrm{~nm}$ was measured with a spectrophotometer, and the protein concentration was calculated using a standard. A total of $5 \mu \mathrm{l}$ cell lysates $(0.5 \mathrm{mg} / \mathrm{ml})$ were added to $195 \mu \mathrm{l}$ of buffer containing an Ac-DEVD-7-amino-4-methylcoumarin (AMC)-conjugated substrate for caspase (Sigma-Aldrich; Merck KGaA). This was followed by $90 \mathrm{~min}$ incubation at $37^{\circ} \mathrm{C}$ in the dark. The concentration of the released AMC was calculated from the fluorescence intensity, which was read using a fluorescence plate reader with the excitation and emission wavelengths of 360 and $460 \mathrm{~nm}$, respectively, and using AMC standard to calculate caspase 3 activity. Data were adjusted according to the protein content. 
Gene expression assay. The MCF-7 cells were seeded in 6 well-plates and allowed to grow for $24 \mathrm{~h}$. Cells were treated with the test compounds, and RNA was isolated using TRIzol ${ }^{\circledR}$ reagent according to the manufacturer's protocol (Sigma-Aldrich; Merck KGaA). Recovered RNA was quantified by using a spectrophotometer to measure the 260/280 nm absorbance ratio. Complementary DNA (cDNA; $1 \mu \mathrm{g}$ ) was prepared by reverse transcription of isolated RNA using the iScript Reverse Transcription Supermix for RT-qPCR. PCR amplification was performed using primers specific for RAC1, cdk2, cdk4 and cdk6, and using $\beta$-actin (ACTB) as an internal control. The PCR primer sequences were as follows: RAC1 (GenBank accession no. NM_018890) forward, 5'ATG-TCC-GTG-CAA-AGT-GGT-ATC3' and reverse, 5'CTC-GGA-TCG-CTT-CGT-CAA-ACA3'; Cdk2 (GenBank accession no. NM_001798) forward, 5'CCA-GGAGTT-ACT-TCT-ATG-CCT-GA3' and reverse, 5'TTC-ATCCAG-GGG-AGG-TAC-AAC3'; Cdk4 (GenBank accession no. NM_000075) forward, 5'ATG-GCT-ACC-TCT-CGA-T AT-GAG-C3' and reverse, 5'CAT-TGG-GGA-CTC-TCA-C AC-TCT3'; Cdk6 (GenBank accession no. NM_001145306) forward, 5'GCT-GAC-CAG-CAG-TAC-GAA-TG3' and reverse, 5'GCA-CAC-ATC-AAA-CAA-CCT-GAC-C3'; ACTB (GenBank accession no. NM_001101) forward, 5'CAT-GTA-CGT-TGC-TAT-CCA-GGC3' and reverse, 5'CTC-CTT-AAT-GTC-ACG-CAC-GAT3'.

qPCR was carried out in a final reaction volume of $20 \mu 1$ containing SYBR Green PCR Master mix (Bio-Rad Laboratories, Inc.), $0.5 \mu \mathrm{M}$ of each target gene and the internal control. The expression of each gene was monitored using an Applied Biosystems ${ }^{\circledR}$ StepOne ${ }^{\mathrm{TM}}$ real-time PCR system (Applied Biosystems; Thermo Fisher Scientific, Inc.) with the following conditions: Denaturation at $95^{\circ} \mathrm{C}$ for $3 \mathrm{~min}$, then amplification by cycling 40 times at $95^{\circ} \mathrm{C}$ for $15 \mathrm{sec}$ and $60^{\circ} \mathrm{C}$ for $30 \mathrm{sec}$. The differences in gene expression levels were calculated using the $2^{-\Delta \Delta \mathrm{Cq}}$ method for relative quantification (26), and expressed as the fold change relative to the untreated control. Data from 3 independent experiments were normalized to the expression of ACTB mRNA, which included on the same PCR array plate as the target genes.

Protein extraction and western blot analysis. The MCF-7 cells were lyzed with RIPA lysis buffer for $30 \mathrm{~min}$ on ice. The lysates were collected, and the protein concentrations were determined using Bradford's reagent, as described in the caspase 3 activity assay. A total of $20 \mu \mathrm{g}$ protein was separated by $12 \%$ SDS-PAGE, and transferred to an Immobilon ${ }^{\circledR}$ polyvinylidene fluoride membrane (EMD Millipore, Billerica, MA, USA). The blots were blocked for $2 \mathrm{~h}$ at room temperature with $5 \%(\mathrm{w} / \mathrm{v})$ skimmed milk in Tris buffered saline containing $0.1 \%$ Tween-20 (TBST). The membrane was probed with each primary antibody at $4^{\circ} \mathrm{C}$ overnight (dilution, 1:1,000). Subsequent to washing with TBST, the blots were incubated with the HRP-conjugated secondary antibody for $2 \mathrm{~h}$ at room temperature (dilution, 1:2,500). The immunoactive bands were detected using an Enhanced Clarity ${ }^{\mathrm{TM}}$ Western enhanced chemiluminescence substrate (Bio-Rad Laboratories, Inc.). Images of the specific protein bands were captured and analyzed using the ImageQuant ${ }^{\mathrm{TM}}$ LAS-4000 and Image Gauge version 3.1 (GE Healthcare Life Sciences, Chalfont, UK).
Statistical analysis. Statistical comparison between the control and treatment groups was analyzed with an unpaired Student's t-test. $\mathrm{P}<0.05$ was considered to indicate a statistically significant difference.

\section{Results}

Effects of simvastatin and doxorubicin on MCF-7 cellular viability and colony formation efficacy. To evaluate the cytotoxicity of simvastatin with or without doxorubicin, the MCF-7 cells were exposed to simvastatin and doxorubicin and assessed for viability by the SRB assay. The results demonstrated that cell growth was inhibited after 24 and $48 \mathrm{~h}$ of treatment, with simvastatin $\mathrm{IC}_{50}$ values of $44.8 \pm 3.8 \mu \mathrm{M}$ at $24 \mathrm{~h}$ and $26.3 \pm 3.1 \mu \mathrm{M}$ at $48 \mathrm{~h}(\mathrm{P}<0.05$, Fig. $1 \mathrm{~A})$, and doxorubicin $\mathrm{IC}_{50}$ values of $5.2 \pm 0.2 \mu \mathrm{M}$ at $24 \mathrm{~h}$ and $1.8 \pm 0.1 \mu \mathrm{M}$ at $48 \mathrm{~h}(\mathrm{P}<0.05$, Fig. 1B) in a dose- and time-dependent manner. The combination of simvastatin and doxorubicin significantly enhanced cytotoxicity (Fig. 1C).

To determine the effect of simvastatin and doxorubicin on the longer-term viability and replicative potential of the MCF-7 cells, a colony formation assay was used. Treatment with simvastatin alone caused a dose-dependent decrease in the colony forming ability of the MCF-7 cells (Fig. 1D). When simvastatin and doxorubicin were used in combination, colony formation was significantly reduced compared with simvastatin treatment alone (Fig. $1 \mathrm{E}$ and $\mathrm{F} ; \mathrm{P}<0.05$ ). These results indicated that simvastatin enhances the activity of doxorubicin in breast cancer cells, and prompted the investigation of the mechanism(s) by which this increase in activity occurs.

Effects of simvastatin and doxorubicin on RACl and downstream gene expression. To investigate whether simvastatin enhances the effects of doxorubicin on the cell cycle regulator RAC1, mRNA expression of RAC1, cdk2, cdk4 and cdk6 were measured. The treatment of cells with a combination of simvastatin and doxorubicin decreased RAC1 mRNA expression significantly more than treatment with simvastatin or doxorubicin alone (Fig. 2A; $\mathrm{P}<0.05$ ). Cdk2 mRNA expression was reduced by simvastatin and doxorubicin individually; however, there was no additive effect when the two were used in combination (Fig. 2B; $\mathrm{P}<0.05$ ). Notably, it was observed that simvastatin or doxorubicin treatment significantly reduced cdk4 and cdk6, and that the combination treatment exhibited an additive effect when compared with simvastatin or doxorubicin treatment alone (Fig. $2 \mathrm{C}$ and $\mathrm{D} ; \mathrm{P}<0.05$ ).

\footnotetext{
Effects of simvastatin and doxorubicin on ROS and caspase 3 activity. To establish the mechanism of action by which simvastatin sensitizes MCF-7 cells to doxorubicin, the intracellular accumulation of ROS was also monitored by the DHE-enhanced chemiluminescence method. Simvastatin induced intracellular ROS production in the MCF-7 cells (Fig. 3A, P<0.05), and cells treated with simvastatin in combination with doxorubicin demonstrated higher ROS production compared with those treated with simvastatin or doxorubicin alone (Fig. 3B, P<0.05). The involvement of mitochondria in simvastatin- and doxorubicin-induced cytotoxicity was investigated by measuring the extent of caspase 3 activity. The results
} 

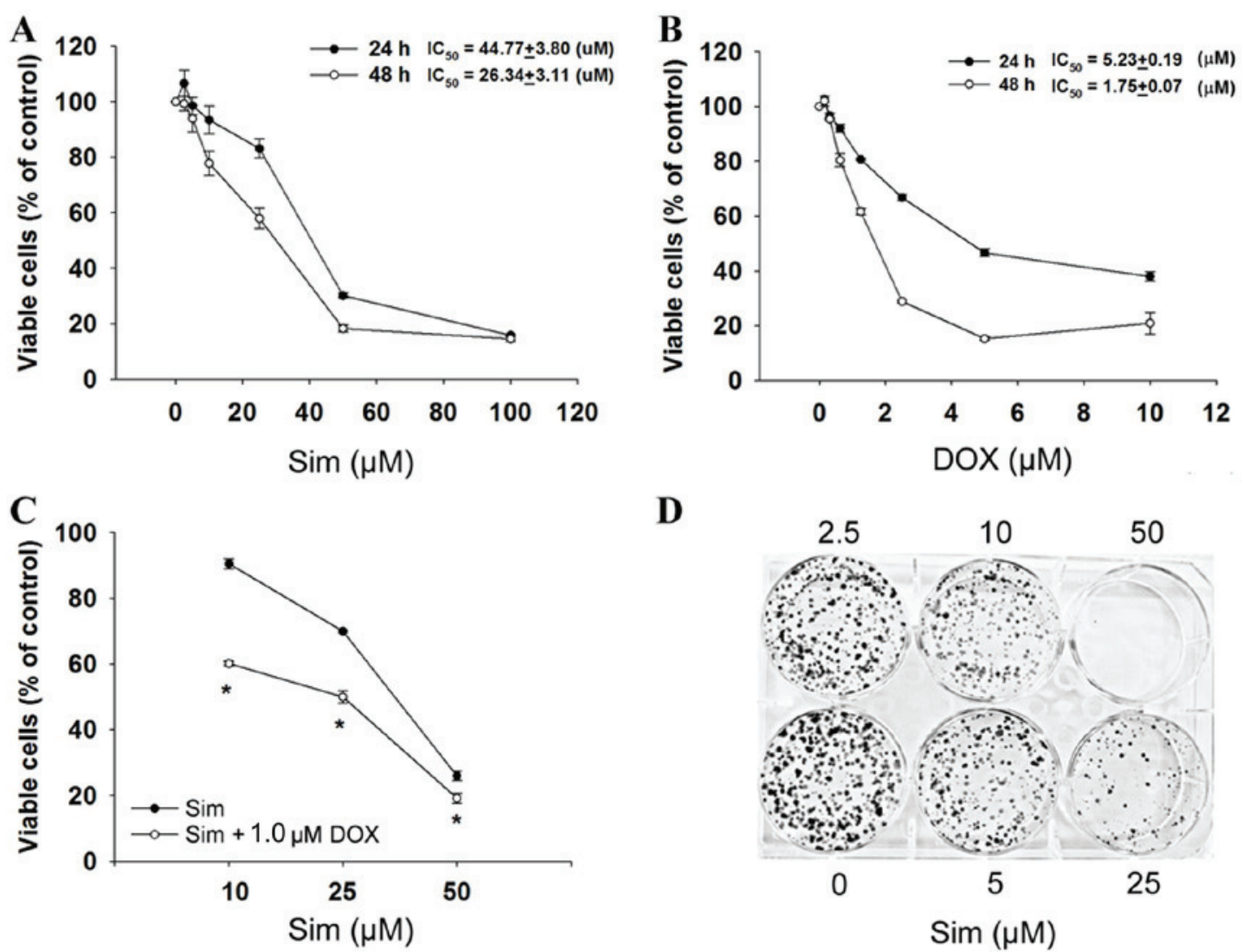

D

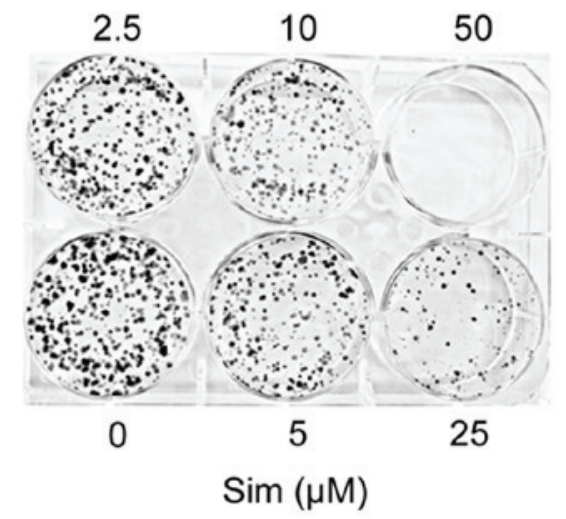

$\mathbf{E}$
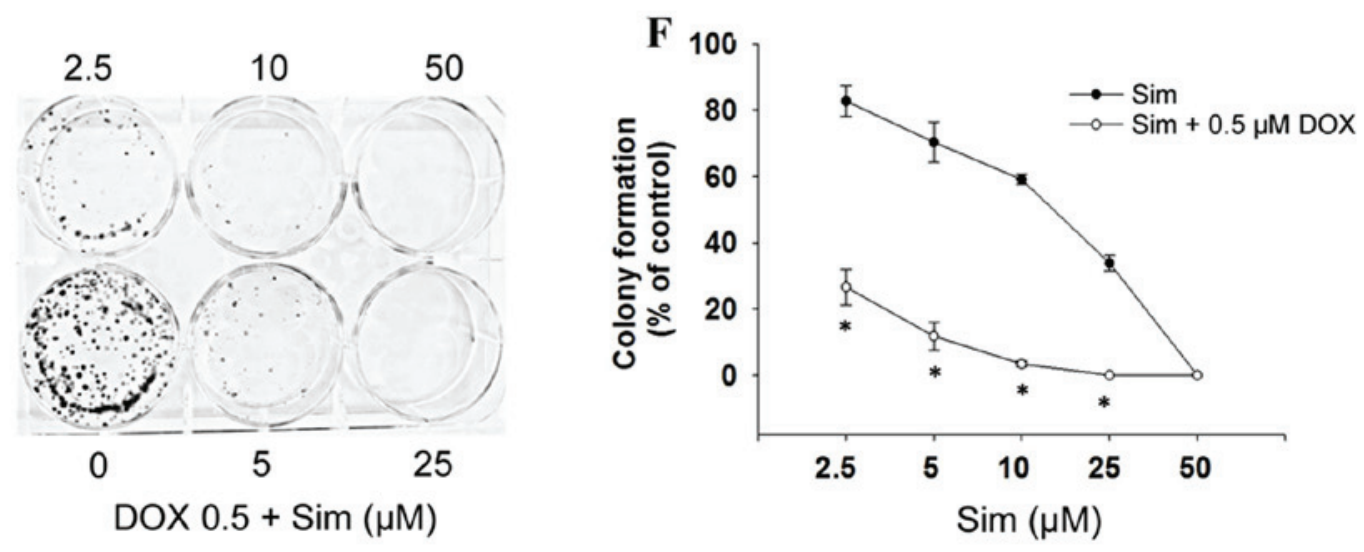

Figure 1. Effects of sim and DOX on MCF-7 cell growth. (A) Cells were treated with 0-100 $\mu \mathrm{M}$ sim, (B) 0-10 $\mu \mathrm{M}$ DOX for 24-48 h or (C) 10-50 $\mu \mathrm{M}$ sim combined with $1 \mu \mathrm{M}$ DOX for $24 \mathrm{~h}$. Subsequent to treatment, cell numbers were determined by the sulforhodamine B assay. Results are presented as the percentage of the control. Cells were then grown in 6-well plates and treated with (D) 0-50 $\mu \mathrm{M}$ sim or (E and F) $0-50 \mu \mathrm{M}$ sim with or without $0.5 \mu \mathrm{M}$ DOX, for $24 \mathrm{~h}$. After 14 days, cells were stained with $0.5 \%$ crystal violet, imaged and counted. Figures are representative of 3 independent experiments. The graph shows percentage colony formation relative to the control. Data are presented as the mean \pm standard deviation calculated from 3 independent experiments. ${ }^{*} \mathrm{P}<0.05$ vs. control. Sim, simvastatin; DOX, doxorubicin.

revealed that treatment with simvastatin increased caspase 3 activity (Fig. 3C, $\mathrm{P}<0.05$ ), and that the combination of simvastatin and doxorubicin increased caspase 3 activity, to a greater extent than treatment with simvastatin alone (Fig. 3D, $\mathrm{P}<0.05)$.

Effects of simvastatin and doxorubicin on protein-related apoptosis. To understand how simvastatin may enhance doxorubicin cytotoxicity in MCF-7 cells, the level of proteins associated with cell survival and apoptosis, including p21, cyclin D1, caspase 3 and cytochrome c, were assessed with western blotting (Fig. 4A-E).
The results revealed that the level of p21 was significantly altered in all treatment groups; p21 was increased following treatment with doxorubicin, decreased following treatment with simvastatin and increased by the combination of doxorubicin with simvastatin, to a greater extent than treatment with doxorubicin or simvastatin alone (Fig. 4B; $\mathrm{P}<0.05$ ). Cyclin D1 levels did not change significantly following treatment with simvastatin; however, treatment with doxorubicin or the combination significantly suppressed cyclin D1 levels (Fig. 4C; $\mathrm{P}<0.05)$. Caspase 3 levels were not significantly altered by treatment with doxorubicin alone; however, they were significantly increased following treatment with simvastatin 

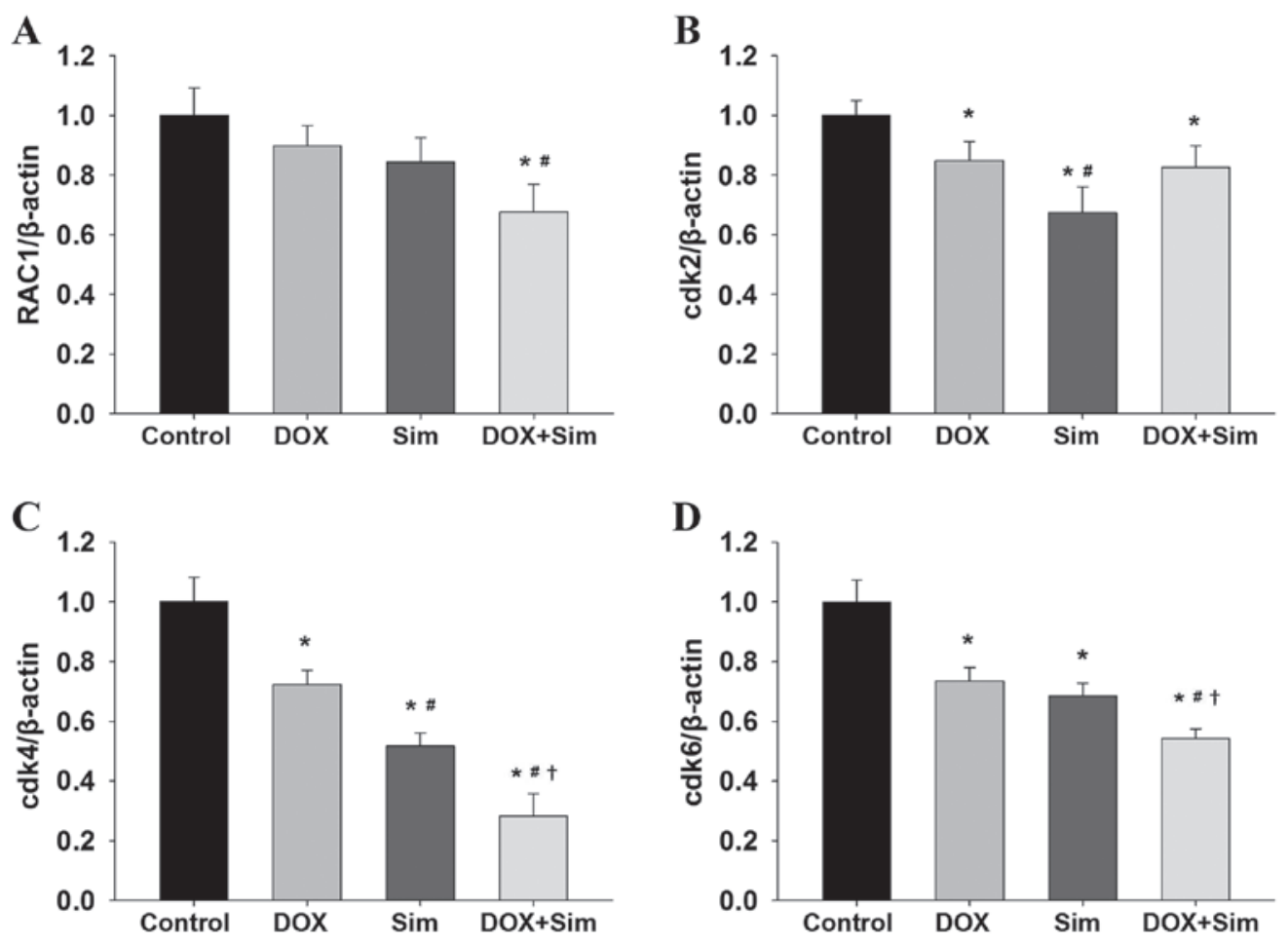

Figure 2. Effects of sim and DOX on the gene expression of (A) RAC1, (B) Cdk2, (C) Cdk4 and (D) Cdk6 in MCF-7 cells. Cells were treated with $50 \mu \mathrm{M}$ sim and $1 \mu \mathrm{M}$ of DOX, alone and in combination for $24 \mathrm{~h}$, and total RNA was prepared and analyzed by quantitative polymerase chain reaction. Data are presented as the mean \pm standard deviation, calculated from 3 independent experiments. ${ }^{*} \mathrm{P}<0.05$ vs. untreated control group; ${ }^{*} \mathrm{P}<0.05$ vs. DOX group; ${ }^{\circ} \mathrm{P}<0.05$ vs. sim group. Sim, simvastatin; DOX, doxorubicin; RAC1, Ras-related C3 botulinum toxin substrate 1; Cdk, cyclin-dependent kinase.
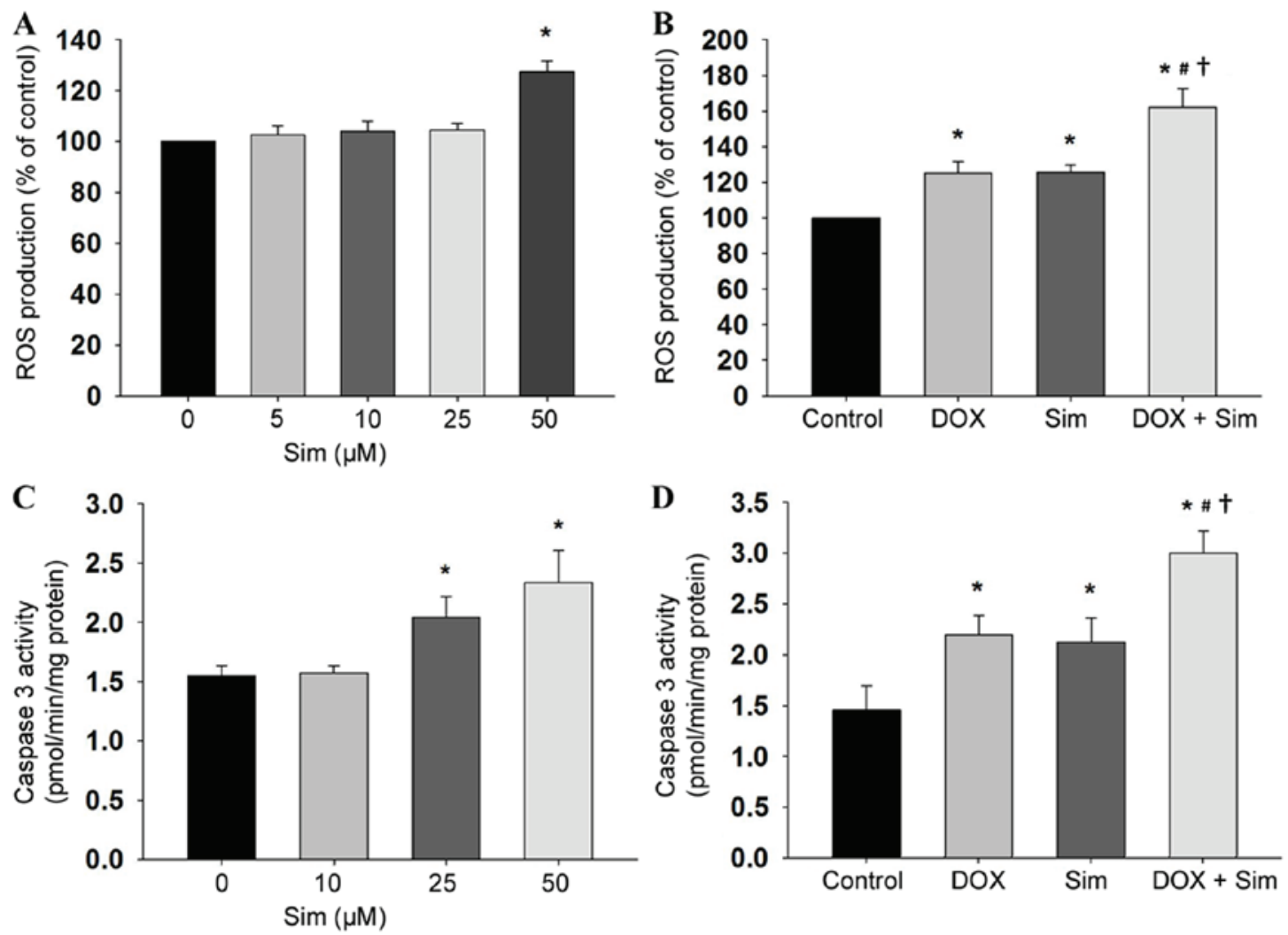

Figure 3. Effects of sim and DOX on ROS production and caspase 3 activity in MCF-7 cells. Cells were seeded in black 96-well culture plates for 24 h. Cells were then treated with (A) $0-50 \mu \mathrm{M} \operatorname{sim}$ or (B) $50 \mu \mathrm{M}$ sim in combination with $1 \mu \mathrm{M}$ DOX for 90 min and assessed for ROS production using $25 \mu \mathrm{M}$ dihydroethidium. Cells were seeded, and treated (C) with sim doses 0-50 $\mu \mathrm{M}$ or (D) sim with, or without, $1 \mu \mathrm{M} \mathrm{DOX}$, for $24 \mathrm{~h}$. The total cell lysates were assayed for caspase 3 activity using specific fluorogenic Ac-DEVD-7-amino-4-methylcoumarin substrates for caspase 3 . Data are presented as the mean \pm standard deviation, calculated from 3 independent experiments. ${ }^{~} \mathrm{P}<0.05$ vs. untreated control group; ${ }^{\#} \mathrm{P}<0.05$ vs. DOX group; ${ }^{\prime} \mathrm{P}<0.05$ vs. sim group. Sim, simvastatin; DOX, doxorubicin; ROS, reactive oxygen species. 


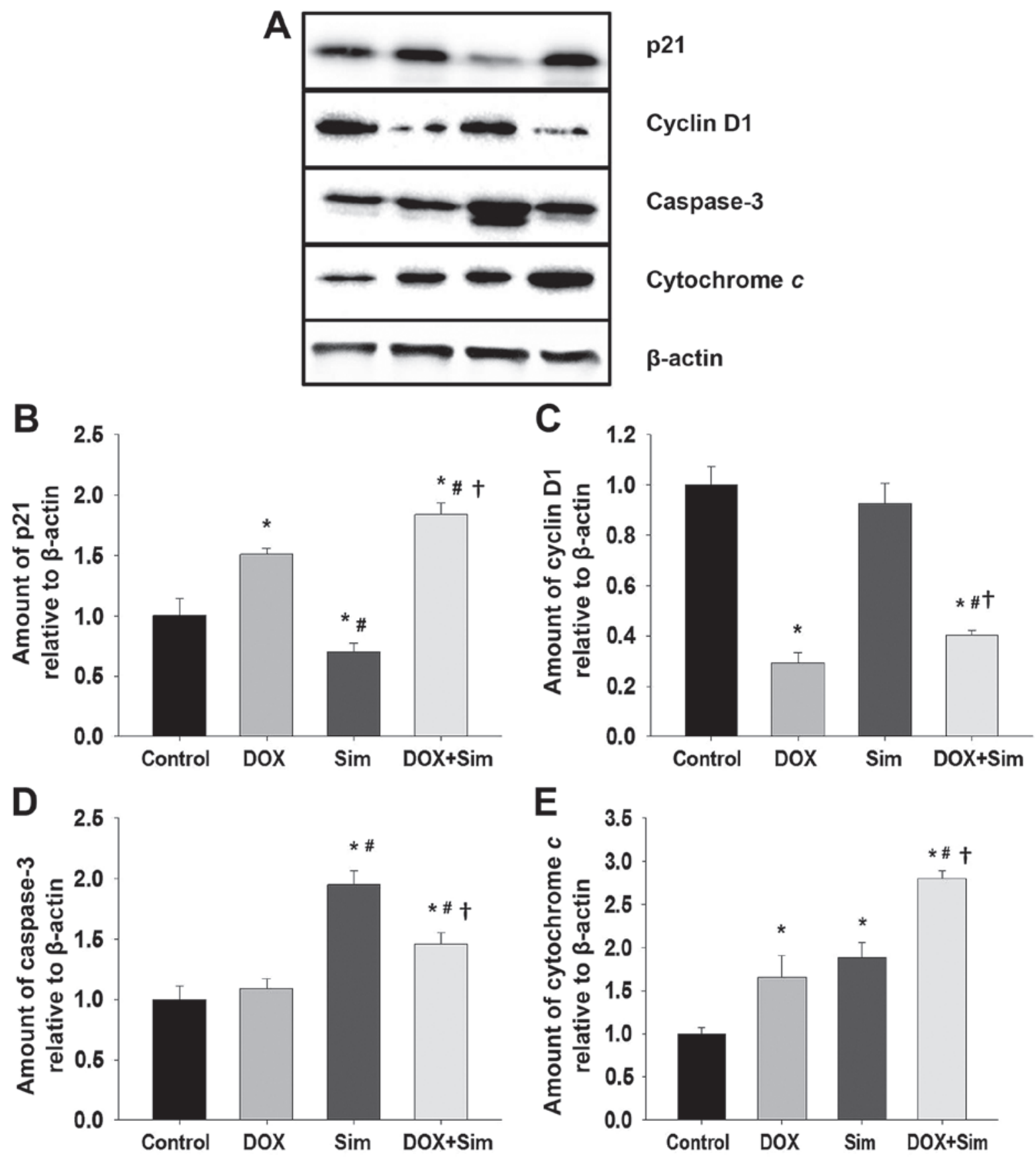

Figure 4. Effects of sim and DOX on the level of proteins associated with growth and apoptosis. MCF-7 cells were treated with $50 \mu \mathrm{M}$ sim or $1 \mu \mathrm{M}$ DOX, individually or combined. Whole cell extracts were prepared and subjected to western blot analysis. (A) The western blot was used to compare the relative protein expression of (B) p21, (C) cyclin D1, (D) caspase 3 and (E) cytochrome c. The levels of each target protein were normalized to the loading control, $\beta$-actin. Data is displayed as the mean of 3 independent experiments \pm standard error of the mean. ${ }^{*} \mathrm{P}<0.05$ vs. untreated control group; ${ }^{*} \mathrm{P}<0.05 \mathrm{vs}$. DOX group; ${ }^{\top} \mathrm{P}<0.05$ vs. sim group. Sim, simvastatin; DOX, doxorubicin.

or the combination treatment (Fig. 4D; $\mathrm{P}<0.05$ ) Cytochrome c protein levels were significantly increased in all treatment groups. The doxorubicin and simvastatin combination had a significantly greater effect on cytochrome c levels than doxorubicin or simvastatin alone (Fig. $4 \mathrm{E} ; \mathrm{P}<0.05$ ).

The combination of doxorubicin with simvastatin stimulated a significant increase in $\mathrm{p} 21$, cytochrome $\mathrm{c}$ and caspase 3 protein levels, and a significant reduction in cyclin D1 protein level. It was also associated with a marked increase in MCF-7 cell death, confirming the potentiating effect of simvastatin upon doxorubicin treatment of breast cancer cells.

\section{Discussion}

Simvastatin is one of the most frequently prescribed drugs due to the efficacy and low toxicity when used to treat hyperlipidemia (27). Previously, statins have been identified to reduce proliferation and induce apoptosis in several cancer cells (28). In the present study, the mechanisms by which simvastatin reduces the rates of cell proliferation and increases the rate of cell death in the doxorubicin-treated breast cancer line MCF-7 cell line were investigated. The results suggest that simvastatin potentiation of doxorubicin-induced cell death 
is accompanied by a suppression of the cell cycle regulator protein RAC1 signaling pathway. The enhanced cytotoxicity of the combination treatment is possibly due to an induction in intracellular ROS formation, leading to increased levels of p21, cytochrome c, and caspase 3 and decreased cyclin D1 levels. This may be associated with the mechanism for MCF-7 breast cancer cell sensitization to anticancer drugs and the induction of cell death. Therefore, simvastatin may potentially be used in the prevention and treatment of breast cancer.

Statins or HMG-CoA reductase inhibitors are drugs commonly used for the treatment of hypercholesterolemia. Additionally, statins exhibit a number of effects on cancer cells (29) including inhibition of cancer cell growth, metastasis and invasion, angiogenesis and the induction of apoptosis. By inhibiting the mevalonic acid pathway, statins may reduce the levels of the isoprenoid intermediates FPP and GGPP (22). These intermediates are critical for post-translational modification of the intracellular G-proteins, including Rho, Rac, and Ras, which regulate the signal transduction of several proteins. These proteins, in turn, are essential for the gene transcription involved in cellular proliferation, differentiation and apoptosis (29). RAC1 is overexpressed in a number of tumors and serves a critical role in cytoskeleton reorganization, cell migration and cell survival (24). An overexpression of RAC1 is associated with the progression, including the metastasis and staging, of human breast cancer (30).

A role for $\mathrm{RAC1}$ in the activation of extracellular signal-regulated kinases (ERK) $1 / 2$ and phosphoinositide 3-kinase/protein kinase B pro-survival signaling was also identified and demonstrated to promote cell survival $(30,31)$. The direct suppression of RAC1 activity induces apoptosis and cell cycle arrest in breast cancer cells (25). In the present study, simvastatin significantly inhibited breast cancer cell proliferation with $\mathrm{IC}_{50}$ values in the low micromolar range. This result is concomitant with the data of previous studies $(16,18)$. Simvastatin stimulates cell cycle arrest and apoptosis in a number of cancer cell types (32) via the intracellular signaling mechanisms of RAC1 and the associated downstream pathway. Cell cycle progression is controlled by Cdk activity (33). The cyclin D1-Cdk4/6 complex also promotes G1 phase cell-cycle progression by modulating the Cdk inhibitor p21 $(34,35)$. RAC1 suppression may inhibit the cyclin-Cdk complex, leading to the activation of $\mathrm{p} 21$ and inhibition of cellular proliferation.

The results of the present study indicate that treatment with simvastatin or doxorubicin alone significantly inhibits RAC1, Cdk4 and Cdk6 mRNA expression after $24 \mathrm{~h}$, whilst combination of the two drugs results in increased activity. Cdk2 is also inhibited by treatment with simvastatin or doxorubicin alone, but in combination this inhibitory effect is not greater compared with that observed with doxorubicin alone. Similar to these observations, a previous study revealed that a blockade of RAC1 activity induces cell cycle arrest or apoptosis in breast cancer cells (25).

In addition to inhibiting the proliferation of MCF-7 cells, the ability of simvastatin to induce apoptosis has been demonstrated. Simvastatin-induced apoptosis was characterized by increased levels of caspase 3, cytochrome c and intracellular ROS. Several studies have revealed that ROS are key signaling molecules in mammalian cells. An accumulation of ROS is directly correlated with mitochondrial dysfunction and promotion of cell apoptosis (36). The results of the present study suggest that simvastatin induced ROS production in a concentration-dependent manner. In combination simvastatin and doxorubicin generated even larger quantities of ROS, a result indicative of an additive effect. This is potentially a key reason why MCF-7 cell apoptosis is induced by simvastatin and doxorubicin. The observation of the present study that a combination of simvastatin and doxorubicin increased cytochrome c protein expression and caspase 3 activity more compared with each drug individually is consistent with the hypothesis that simvastatin sensitizes MCF-7 cells.

The present study identified that simvastatin inhibited MCF-7 cell proliferation and colony formation in a dose-dependent manner and, notably, that it enhanced the activity of doxorubicin. The effect on cell cycle progression was also investigated in the present study by measuring p21 and cyclin D1 protein expression. Simvastatin and doxorubicin treatment resulted in an increase in p21, and a decrease in cyclin D1 expression level. These data suggest that simvastatin enhances doxorubicin-induced cancer cell death by inhibiting cell cycle progression (37).

In conclusion, the present study has demonstrated that simvastatin enhances doxorubicin cytotoxicity towards MCF-7 cells through an inhibition of the RAC1 pathway and induction of caspase- and cytochrome c-dependent apoptosis in a process involving oxidative stress. These data also reveal that the $\mathrm{Cdk}$ inhibitor $\mathrm{p} 21$ is activated in the process of simvastatin-induced cell death, leading to an inhibition of cell cycle progression. These results contribute to the current understanding of the molecular mechanisms of simvastatin, and provide a basis for future studies seeking to validate the mevalonate pathway as a novel therapeutic target. The inclusion of statins in anticancer treatment regimens may potentially reduce the quantity of anticancer drugs required to achieve therapeutic effects and thereby reduce the side effects associated with cancer treatment.

\section{Acknowledgements}

The present study was supported by the Office of the Higher Education Commission (grant no., 2558A10962234), a grant from the Mahasarakham University (MSU) Faculty of Medicine, a Mahasarakham University 2016 Thailand Research Fund (Grant no. TRG5780254) and the National Research Council of Thailand (Grant no. 2559A10902073). The authors would like to thank Dr. Tim Cushnie (Faculty of Medicine, Mahasarakham University, Thailand) for language-editing the manuscript.

\section{References}

1. Berry DA, Cronin KA, Plevritis SK, Fryback DG, Clarke L, Zelen M, Mandelblatt JS, Yakovlev AY, Habbema JD and Feuer EJ; Cancer Intervention and Surveillance Modeling Network (CISNET) Collaborators: Effect of screening and adjuvant therapy on mortality from breast cancer. N Engl J Med 353: 1784-1792, 2005.

2. Ferlay J, Steliarova-Foucher E, Lortet-Tieulent J, Rosso S, Coebergh JW, Comber H, Forman D and Bray F: Cancer incidence and mortality patterns in Europe: Estimates for 40 countries in 2012. Eur J Cancer 49: 1374-1403, 2013. 
3. Pagani O, Senkus E, Wood W, Colleoni M, Cufer T, Kyriakides S, Costa A, Winer EP and Cardoso F; ESO-MBC Task Force: International guidelines for management of metastatic breast cancer: Can metastatic breast cancer be cured? J Natl Cancer Inst 102: 456-463, 2010.

4. O'Driscoll L and Clynes M: Biomarkers and multiple drug resistance in breast cancer. Curr Cancer Drug Targets 6: 365-384, 2006.

5. Coley HM: Mechanisms and strategies to overcome chemotherapy resistance in metastatic breast cancer. Cancer Treat Rev 34: 378-390, 2008.

6. Istvan ES and Deisenhofer J: Structural mechanism for statin inhibition of HMG-CoA reductase. Science 292: 1160-1164, 2001.

7. Hoeg JM and Brewer HB Jr: 3-Hydroxy-3-methylglutarylcoenzyme A reductase inhibitors in the treatment of hypercholesterolemia. JAMA 258: 3532-3536, 1987.

8. Watanabe Y, Ito T, Shiomi M, Tsujita Y, Kuroda M, Arai M, Fukami $\mathrm{M}$ and Tamura A: Preventive effect of pravastatin sodium, a potent inhibitor of 3-hydroxy-3-methylglutaryl coenzyme A reductase, on coronary atherosclerosis and xanthoma in WHHL rabbits. Biochim Biophys Acta 960: 294-302, 1988.

9. Downs JR, Clearfield M, Weis S, Whitney E, Shapiro DR, Beere PA, Langendorfer A, Stein EA, Kruyer W and Gotto AM Jr: Primary prevention of acute coronary events with lovastatin in men and women with average cholesterol levels: Results of AFCAPS/TexCAPS. Air Force/Texas coronary atherosclerosis prevention study. JAMA 279: 1615-1622, 1998.

10. Khush KK and Waters DD: Effects of statin therapy on the development and progression of heart failure: Mechanisms and clinical trials. J Card Fail 12: 664-674, 2006.

11. Qi XF, Kim DH, Yoon YS, Li JH, Jin D, Teng YC, Kim SK and Lee KJ: Fluvastatin inhibits expression of the chemokine MDC/CCL22 induced by interferon-gamma in HaCaT cells, a human keratinocyte cell line. Br J Pharmacol 157: 1441-1450, 2009.

12. Blum A and Shamburek R: The pleiotropic effects of statins on endothelial function, vascular inflammation, immunomodulation and thrombogenesis. Atherosclerosis 203: 325-330, 2009.

13. Elewa HF, El-Remessy AB, Somanath PR and Fagan SC: Diverse effects of statins on angiogenesis: New therapeutic avenues. Pharmacotherapy 30: 169-176, 2010.

14. Cai JP, Chen W, Hou X, Liang LJ, Hao XY and Yin XY: Simvastatin enhances the chemotherapeutic efficacy of S-1 against bile duct cancer: E2F-1/TS downregulation might be the mechanism. Anticancer Drugs 24: 1020-1029, 2013.

15. Kamigaki M, Sasaki T, Serikawa M, Inoue M, Kobayashi K, Itsuki H, Minami T, Yukutake M, Okazaki A, Ishigaki T, et al: Statins induce apoptosis and inhibit proliferation in cholangiocarcinoma cells. Int J Oncol 39: 561-568, 2011.

16. Shen Y, Du Y, Zhang Y and Pan Y: Synergistic effects of combined treatment with simvastatin and exemestane on MCF-7 human breast cancer cells. Mol Med Rep 12: 456-462, 2015.

17. Spampanato C, De Maria S, Sarnataro M, Giordano E, Zanfardino M, Baiano S, Cartenì M and Morelli F: Simvastatin inhibits cancer cell growth by inducing apoptosis correlated to activation of Bax and down-regulation of BCL-2 gene expression. Int J Oncol 40: 935-941, 2012.

18. Miller T, Yang F and Wise CE, Meng F, Priester S, Munshi MK, Guerrier M, Dostal DE and Glaser SS: Simvastatin stimulates apoptosis in cholangiocarcinoma by inhibition of Racl activity. Dig Liver Dis 43: 395-403, 2011.
19. Werner M, Sacher J and Hohenegger M: Mutual amplification of apoptosis by statin-induced mitochondrial stress and doxorubicin toxicity in human rhabdomyosarcoma cells. Br J Pharmacol 143: 715-724, 2004

20. Sassano A and Platanias LC: Statins in tumor suppression. Cancer Lett 260: 11-19, 2008

21. KusamaT,MukaiM,IwasakiT,TatsutaM,Matsumoto Y,AkedoH, Inoue $\mathrm{M}$ and Nakamura $\mathrm{H}$ : 3-hydroxy-3-methylglutaryl-coenzyme a reductase inhibitors reduce human pancreatic cancer cell invasion and metastasis. Gastroenterology 122: 308-317, 2002.

22. Wong WW, Dimitroulakos J, Minden MD and Penn LZ: HMG-CoA reductase inhibitors and the malignant cell: The statin family of drugs as triggers of tumor-specific apoptosis. Leukemia 16: 508-519, 2002

23. Jaffe AB and Hall A: Rho GTPases: Biochemistry and biology. Annu Rev Cell Dev Biol 21: 247-269, 2005.

24. Bosco EE, Mulloy JC and Zheng Y: Rac1 GTPase: A "Rac" of all trades. Cell Mol Life Sci 66: 370-374, 2009.

25. Yoshida T, Zhang Y, Rivera Rosado LA, Chen J, Khan T, Moon SY and Zhang B: Blockade of Racl activity induces G1 cell cycle arrest or apoptosis in breast cancer cells through downregulation of cyclin D1, survivin, and X-linked inhibitor of apoptosis protein. Mol Cancer Ther 9: 1657-1668, 2010.

26. Livak KJ and Schmittgen TD: Analysis of relative gene expression data using real-time quantitative PCR and the 2(-Delta Delta C(T)) Method. Methods 25: 402-408, 2001.

27. Goldstein JL and Brown MS: Regulation of the mevalonate pathway. Nature 343: 425-430, 1990

28. Martirosyan A, Clendening JW, Goard CA and Penn LZ: Lovastatin induces apoptosis of ovarian cancer cells and synergizes with doxorubicin: Potential therapeutic relevance. BMC Cancer 10: 103, 2010.

29. Hindler K, Cleeland CS, Rivera E and Collard CD: The role of statins in cancer therapy. Oncologist 11: 306-315, 2006.

30. Schnelzer A, Prechtel D, Knaus U, Dehne K, Gerhard M, Graeff H, Harbeck N, Schmitt M and Lengyel E: Rac1 in human breast cancer: Overexpression, mutation analysis, and characterization of a new isoform, Raclb. Oncogene 19: 3013-3020, 2000.

31. Eblen ST, Slack JK, Weber MJ and Catling AD: Rac-PAK signaling stimulates extracellular signal-regulated kinase (ERK) activation by regulating formation of MEK1-ERK complexes. Mol Cell Biol 22: 6023-6033, 2002.

32. Saito A, Saito N, Mol W, Furukawa H, Tsutsumida A, Oyama A, Sekido M, Sasaki S and Yamamoto Y: Simvastatin inhibits growth via apoptosis and the induction of cell cycle arrest in human melanoma cells. Melanoma Res 18: 85-94, 2008.

33. Sherr CJ and Roberts JM: CDK inhibitors: Positive and negative regulators of G1-phase progression. Genes Dev 13: 1501-1512, 1999.

34. Fournier AK, Campbell LE, Castagnino P, Liu WF, Chung BM, Weaver VM, Chen CS and Assoian RK: Rac-dependent cyclin D1 gene expression regulated by cadherin- and integrin-mediated adhesion. J Cell Sci 121: 226-233, 2008.

35. Gartel AL and Tyner AL: The role of the cyclin-dependent kinase inhibitor p21 in apoptosis. Mol Cancer Ther 1: 639-649, 2002.

36. D'Autréaux B and Toledano MB: ROS as signalling molecules: Mechanisms that generate specificity in ROS homeostasis. Nat Rev Mol Cell Biol 8: 813-824, 2007.

37. Sadeghi-Aliabadi H, Minaiyan M and Dabestan A: Cytotoxic evaluation of doxorubicin in combination with simvastatin against human cancer cells. Res Pharm Sci 5: 127-133, 2010. 